\title{
Videolaryngoscopy: A Discrete Approach to Awake Intubation!
}

\author{
Ratnesh K. Shukla ${ }^{1}$ Vattipalli Sameera ${ }^{1}$ Arvind Chaturvedi ${ }^{1}$ Indu Kapoor ${ }^{1}$
}

\author{
${ }^{1}$ Department of Neuroanaesthesiology and Critical Care, \\ Neurosciences Centre, All India Institute of Medical Sciences \\ (AlIMS), New Delhi, India
}

J Neuroanaesthesiol Crit Care 2019;6:48

Airway is a concern in neurosurgical patients for many reasons. Presence of comorbidities in addition to difficult airway scenario brings challenge to anesthesiologists of another level. A clear understanding of difficult airway algorithm and timely intervention of an appropriate airway device play a critical role in acute management in neurosurgical patients.

We report a case of a 47-year-old woman with Arnold-Chiari malformation posted for foramen magnum decompression under general anesthesia. She was a known case of rheumatoid arthritis for past 12 years on treatment. Her airway examination showed Mallampati grade II and her mouth opening was two fingerbreadths. Neck extension was restricted due to the underlying pathology. In view of anticipated difficult intubation, she was counseled for the awake intubation a day before surgery. She was given $0.2 \mathrm{mg}$ of glycopyrrolate through intramuscular route 30 minutes prior to surgery. A written informed consent was taken from the patient. Superior laryngeal nerve block with $1.5 \mathrm{~mL}$ of $2 \%$ lignocaine bilaterally followed by recurrent laryngeal nerve block with $3 \mathrm{~mL}$ of $2 \%$ lignocaine was given successfully under aseptic precaution. Posterior pharyngeal wall and posterior aspect of tongue were anesthetized with $10 \%$ lignocaine spray. She was provided supplemental oxygen with nasal prongs at $4 \mathrm{~L} / \mathrm{min}$. Since our fiberoptic bronchoscope was not in a functional state, we planned for awake intubation using video laryngoscope (C-MAC). We used video laryngoscope blade size D. Airway was secured with a 7.0-mm internal diameter cuffed polyvinyl chloride (PVC) tube with the help of a bougie. She was comfortable throughout the procedure and maintained peripheral oxygen saturation of 95 to $98 \%$. After successful completion of the surgery, she was shifted to neurosurgical intensive care unit for elective ventilation. She was extubated next day morning uneventfully.

Awake fiberoptic intubation has been a popular choice for the management of the anticipated difficult airway. ${ }^{1}$ However, fiberoptic intubation remains a challenging technique to learn, and continuous practice is needed to maintain the skill apart from having a learning curve. ${ }^{2}$ The Fourth National Audit Project of the Royal College of Anaesthetists (NAP4) reported that awake fiberoptic intubation was not used as the primary airway plan for many patients with high-risk. ${ }^{3}$ The use of videolaryngoscopes for awake intubation is a relatively new

Address for correspondence Indu Kapoor, MD, Department of Neuroanaesthesiology and Critical Care, Neurosciences Centre, All India Institute of Medical Sciences, New Delhi-110029, India (e-mail:dr.indu.me@gmail.com).

technique. Cochrane database systematic review concluded that failed intubations are significantly fewer when videolaryngoscopy is used compared with fiberoptic bronchoscope in anticipated difficult airway situation. ${ }^{4}$ According to Rosenstock et al, where they compared awake fiberoptic bronchoscopy and videolaryngoscope in patients with difficult airway observed that both groups did not differ in median time to tracheal intubation or first-attempt success; however, oxygen desaturation to $<90 \%$ developed in $21 \%$ of the fiberoptic group and $10 \%$ of the videolaryngoscope group. ${ }^{5}$ Videolaryngoscopes provide a wider view of the airway, less loss of orientation, and no limitation on the tracheal tube diameter use in comparison to fiberoptic bronchoscopes. Awake videolaryngoscopic intubation is equally fast and successful as awake fiberoptic intubation. Through our case, we would like to emphasize that the videolaryngoscope should always be the part of difficult airway management armamentarium, whenever it is contemplated.

\section{Conflict of Interest}

None declared.

\section{References}

1 Apfelbaum JL, Hagberg CA, Caplan RA, et al; American Society of Anesthesiologists Task Force on Management of the Difficult Airway. Practice guidelines for management of the difficult airway: an updated report by the American Society of Anesthesiologists Task Force on Management of the Difficult Airway. Anesthesiology 2013;118(2):251-270

2 Fitzgerald E, Hodzovic I, Smith AF. 'From darkness into light': time to make awake intubation with videolaryngoscopy the primary technique for an anticipated difficult airway? Anaesthesia 2015;70(4):387-392

3 Cook TM, Woodall N, Frerk C, et al. The NAP4 Report: Major Complications of Airway Management in the United Kingdom. London: The Royal College of Anaesthetists; 2011

4 Lewis SR, Butler AR, Parker J, Cook TM, Smith AF. Videolaryngoscopy versus direct laryngoscopy for adult patients requiring tracheal intubation. Cochrane Database Syst Rev 2016;11:CD011136

5 Rosenstock CV, Thøgersen B, Afshari A, Christensen AL, Eriksen C, Gätke MR. Awake fiberoptic or awake video laryngoscopic tracheal intubation in patients with anticipated difficult airway management: a randomized clinical trial. Anesthesiology 2012;116(6):1210-1216

DOI https://doi.org/ ISSN 2348-0548.

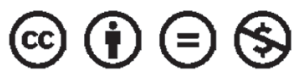

